\title{
Drug resistance and tuberculosis elimination in low-incidence countries
}

\author{
Dennis Falzon', Jean-Pierre Zellweger², Giovanni Battista Migliori ${ }^{3}$ and \\ Ernesto Jaramillo ${ }^{1}$
}

\begin{abstract}
Affiliations: 'lobal TB Programme, World Health Organization, Geneva, Switzerland. ${ }^{2}$ Swiss Lung Association, Berne, Switzerland. ${ }^{3}$ World Health Organization Collaborating Centre for Tuberculosis and Lung Diseases, Fondazione S. Maugeri, Care and Research Institute, Tradate, Italy.
\end{abstract}

Correspondence: Dennis Falzon, Global TB Programme, World Health Organization, 20 avenue Appia, CH-1211 Geneva 27, Switzerland. E-mail: falzondawho.int

0 @ERSpublications

Countries on track to eliminate TB in the 21st century should be vigilant about the threat of drugresistant strains http://ow.ly/AWJ36

Countries that have already reduced their tuberculosis (TB) caseloads to low levels are now embarking on the road to reduce them even further and faster $[1,2]$. In these countries, TB cases now predominate in subgroups of the population that are at greater risk of infection, progression to disease or unfavourable outcome, risks that oftentimes overlap within the same individual [3]. As low TB incidence countries approach the pre-elimination threshold, i.e. moving from $<100 \mathrm{~TB}$ cases per million population per year today to $<10 \mathrm{~TB}$ cases per million, it is expected that the concentration of disease in these subgroups will persist and possibly intensify as a result of the continued, natural attrition of the older population that accounts for many of the native TB cases today [4]. If the declining trend in TB incidence in these countries continues, TB will become rarer. The prospect of having fewer cases in the future does not automatically imply that the task of controlling TB becomes any lighter for national authorities. In fact, cases may become more difficult to find and to treat as a result of patient mobility, absent or incomplete healthcare coverage, lack of entitlements for those with irregular legal status, and other vulnerabilities linked to poverty, substance use, and co-existence of diseases such as HIV and diabetes, in a context of diminishing resources and expertise for $\mathrm{TB}$ case management. The development of resistance to anti-TB medication, which may be potentiated by some of these factors, compounds the picture even further. These epidemiological developments may put the progress towards TB elimination at risk.

The large majority of the TB cases occurring in most of the world and in low TB incidence settings remains drug susceptible and potentially curable with standard, first-line regimens, which have become widely available in recent decades. One of the threats to TB elimination has been the propagation of resistance, much of it fuelled by the improper use of the drugs making up these regimens. The emergence of combined resistance to rifampicin and isoniazid, the two most effective anti-TB medicines today (multidrug-resistant (MDR)-TB), has now become a matter of global concern [5]. While the bulk of the global MDR-TB burden occurs in large, populous, middle-income countries, richer countries with low TB incidence rates are not spared. International clusters of drug-resistant TB cases have involved, among others, western European countries and the USA [6, 7]. In many low TB incidence countries, TB patients of foreign origin are at higher risk of MDR-TB than native patients; in 18 European countries in 2012, for instance, the pooled

D. Falzon and E. Jaramillo are staff members of the World Health Organization (WHO). The authors alone are responsible for the views expressed in this publication and they do not necessarily represent the decisions or policies of WHO. The designations used and the presentation of the material in this publication do not imply the expression of any opinion whatsoever on the part of WHO concerning the legal status of any country, territory, city or area, or of its authorities, nor concerning the delimitation of its frontiers or boundaries.

Received: July 292014 | Accepted after revision: Aug 022014

Conflict of interest: None declared

The content of this work is @ the authors or their employers. Design and branding are @ERS 2014 
odds ratio for MDR-TB in foreign-born versus native TB patients was 2.38 (95\% CI 1.47-3.85) [8]. Persons born in the former Soviet Union have the highest risk of MDR-TB among TB patients in Western Europe [9].

In May 2014, the World Health Assembly passed a landmark resolution endorsing a comprehensive strategy to address TB control in the world after 2015 [10]. One of the determinants of the future success of this strategy will be the manner in which drug resistance patterns will evolve in the world. The forms and speed with which drug-resistant strains will emerge will be closely linked to the practices of antimicrobial use [11]. Conditions that favour the spread of TB, such as poor infection control in congregate settings like hospitals and prisons, can likewise propagate drug-resistant strains even further. The impact on the future TB landscape can be posited. Firstly, immigrants are projected to come to represent a larger proportion of the total population in many high-income countries in the coming decades [12-14]. Many migrants originate from settings at higher risk of $\mathrm{TB}$ and drug-resistant $\mathrm{TB}$ than the host countries. If the proportion of migrants infected with drug-resistant $\mathrm{TB}$ strains who are settling in these countries increases with time, reactivated disease in these individuals is also bound to be more frequently drug-resistant in the coming years than it is today. Secondly, the reproductive fitness of MDR-TB strains (i.e. their capacity to cause disease) in the population could increase, a tendency which appears to be linked to the effectiveness of TB treatment programmes [15]. This would increase the risk of drug resistance among TB patients and, in an extreme-case scenario, highly virulent drug-resistant organisms may outpace the rate of replication of drugsusceptible strains. Thirdly, current treatment regimens for MDR-TB remain unsatisfactory in terms of safety, effectiveness, duration and cost [16]. Treating drug-resistant TB cases will impinge significantly on the national health budgets, particularly if new and expensive therapies become available [17, 18]. Even in several well resourced countries, the likelihood of a successful outcome is $<60 \%$ [8] (fig. 1).

The roadmap for the elimination of TB in low-incidence countries needs to include a number of key elements targeting the prevention, early detection and care of drug resistance. Sustaining commitment and resources for TB control in the face of a dwindling epidemic will be a challenge and requires bold action. The resurgence of TB in the USA from the mid-1980s to the early 1990s, during which MDR-TB outbreaks featured prominently in certain localities, is a vivid reminder of the dangers of relaxing TB control [20]. Normality could only be regained following massive investments in public health and at the expense of much avoidable anxiety, disease and death [21]. The prospect of increased immigration should not trigger counter-productive and inhumane policies, especially towards those who cross borders illegally. Deportation of migrants with TB is likely to deter individuals from seeking adequate care when they need it, and thus fuel improper treatment and transmission within the community. Migration may well be an opportunity to help shore up some of the deficits in TB control in the world [22, 23]. A number of countries have already introduced policies that offer treatment of TB before entry into the host country or immediately after resettlement. Drug resistance needs to be considered in all TB patients, given that more than half of the global burden of MDR-TB occurs in cases with no previous history of TB and many of these may have no manifest risk factors for drug-resistance [24, 25].

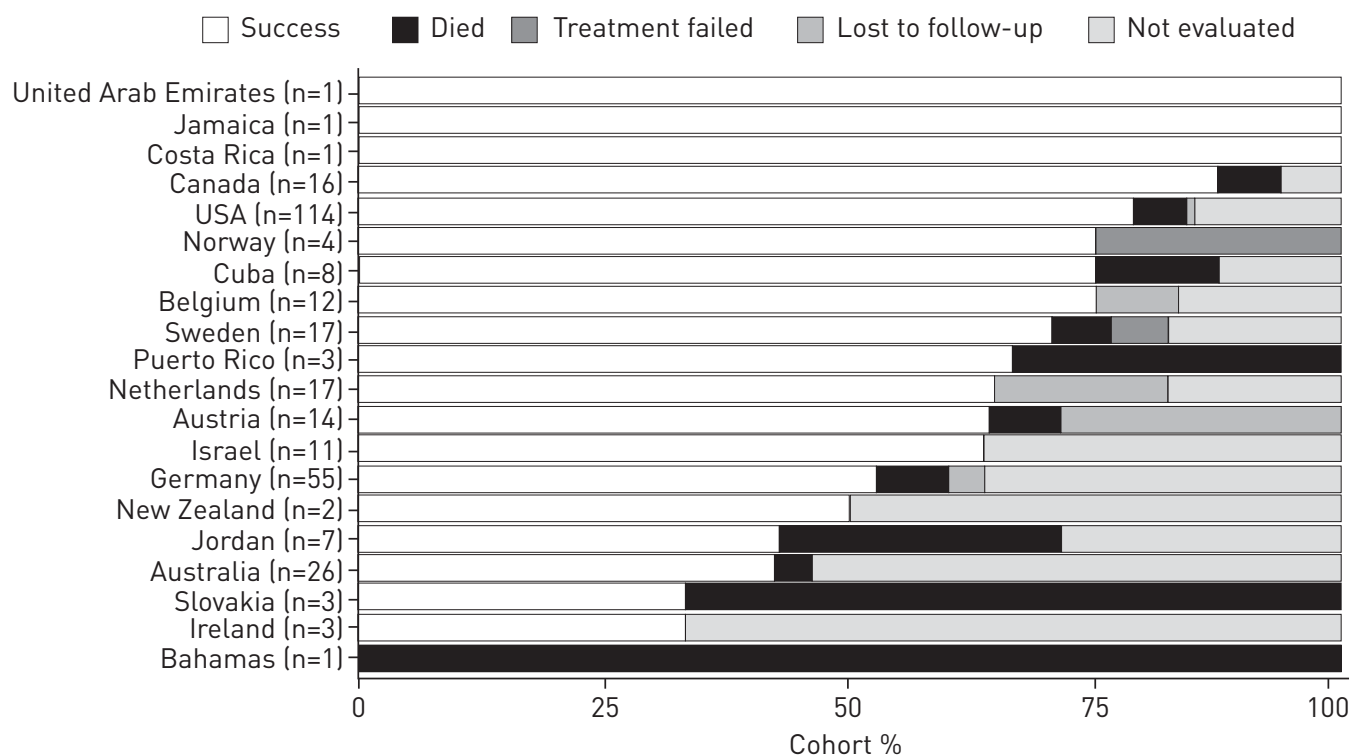

FIGURE 1 Treatment outcomes for patients with multidrug-resistant tuberculosis starting treatment in 2011 in 20 low-incidence countries. Total number of cases in each cohort is shown for each country. Data from [19]. 
Direct support by low-incidence countries for TB control efforts in the countries from where migrants originate, through technical assistance or financial grants, may be a viable option [26].

Unregulated use of second-line drugs and inadequate treatment regimens can generate more drug resistance, perpetuating a vicious cycle, the end-product of which will be patients infected with strains for which no treatment options are available [27]. About 9\% of MDR-TB cases have extensively drug-resistant (XDR)-TB (MDR-TB plus resistance to any fluoroquinolone and any second-line injectable drug), a form of disease associated with very poor outcomes $[28,29]$. By mid-2014, $>100$ countries and territories across the world had documented at least one XDR-TB case, including 22 of the 33 considered to have a low incidence of TB. The disruptive effect of single cases of MDR/XDR-TB on the healthcare resources of countries with small numbers of TB cases (such as Iceland and Malta) is a forewarning to other countries as they advance on their path to elimination. Moreover, cases with resistance beyond XDR-TB have been reported from different settings, including countries targeting elimination [30, 31]. Resistance patterns other than those that we know of today are destined to emerge as new anti-TB medicines are discovered and released on the market; the public health significance of new types of resistance may eclipse in importance that of the MDR/ $\mathrm{XDR}-\mathrm{TB}$ strains as treatment regimens evolve in the coming decades.

The new global TB strategy is projected to deliver fully on its promises only if new diagnostic, preventive and curative tools will start to be implemented on a large scale by about 2025 [10]. Until then, the path to elimination will require the optimisation of prevention and care of drug-resistant TB based upon timeproven approaches to TB control, using the currently available tools more effectively and engaging the collaboration of different actors towards this aim. The World Health Organization has just issued practical guidance on how to implement the programmatic management of drug-resistant TB based on the most recent evidence [32]. First of all, treatment of drug-susceptible disease needs to improve in order to reduce the risk of acquisition of resistance. The low cure rates observed in certain countries for a treatable condition are unacceptable. Secondly, if the control of drug-resistant TB is not to be achieved at the expense of the unnecessary death of many patients who could otherwise be cured, the affected patient will need a rapid diagnosis followed by appropriate treatment. Infection control depends to a large extent upon these patients being rendered noninfectious fast. The difficulties associated with drug-resistant TB treatment makes a patient-centred approach more important, including access to comprehensive social support. Financial enablers, provided alongside other adherence interventions [33], may become more cost-effective when TB control hinges upon a smaller number of cases required to complete their treatment. As TB starts to become rare, so will be the number of specialists and health services available to provide appropriate care. Measures to improve the awareness of healthcare professionals through continuous education, sensitisation about the realities of $\mathrm{TB}$, networking between specialists, exchange of information and support in clinical decision-making for complicated cases could be effective [34,35]. Thirdly, continued surveillance of resistance patterns and programme performance will be required and needs to adapt to a changing environment. Pharmacovigilance will be needed to promote the safer use of anti-TB medicines, and manage adverse drug reactions particularly when new drugs and novel regimens are introduced [36, 37]. Better use of available information technology to facilitate reporting is important. Fourthly, the uninterrupted availability of quality-assured drugs and proper antimicrobial stewardship to ensure their rational use (particularly measures to enhance regulatory structures and assistance in clinical decisions) will be required more than ever. And finally, the management of MDR-TB should be grounded on solid ethical principles, upholding the respect and promotion of human rights, and preventing the discrimination that patients suffer through the stigma attached to the disease. This is particularly relevant when infection control practices infringe upon the fundamental liberties of the patient.

If research is to make a difference to patients with drug-resistant $\mathrm{TB}$, there needs to be a rapid translation of scientific findings into treatment and care practices in the coming years. The development of point-of-care rapid diagnostics for resistance will be crucial [38]. Safer, more affordable and more effective medicines in regimens that are shorter in duration and easier to administer are key to improving treatment outcomes. Repurposing of drugs that have anti-TB activity needs to continue. Studies of the chemoprophylaxis of drugresistant TB will need to inform not only about its effectiveness in protecting the individual contact but also its potential role among the other population-level interventions available for the elimination of TB. And last but not least, evidence of which interventions can improve patient awareness and health-seeking behaviour in lowincidence settings will be needed to make programmes more effective in the face of drug-resistant TB.

\section{References}

Clancy L, Rieder HL, Enarson DA, et al. Tuberculosis elimination in the countries of Europe and other industrialized countries. Eur Respir J 1991; 4: 1288-1295.

2 Lönnroth K, Migliori GB, Raviglione M. Towards tuberculosis elimination in low-incidence countries - reflections from a global consultation. Ann Intern Med 2014 [In press]. 
3 Story A, Murad S, Roberts W, et al. Tuberculosis in London: the importance of homelessness, problem drug use and prison. Thorax 2007; 62: 667-671.

4 Borgdorff MW, van den Hof S, Kremer K, et al. Progress towards tuberculosis elimination: secular trend, immigration and transmission. Eur Respir J 2010; 36: 339-347.

5 Resolution WHA62.15. Prevention and control of multidrug-resistant tuberculosis and extensively drug-resistant tuberculosis. In: WHO, Sixty-second World Health Assembly, Geneva, 18-22 May 2009, Resolutions and decisions; annexes. Geneva, WHO, 2009; pp. 25-29.

6 Devaux I, Kremer K, Heersma H, et al. Clusters of multidrug-resistant Mycobacterium tuberculosis cases, Europe. Emerging Infect Dis 2009; 15: 1052-1060.

7 Quitugua TN, Seaworth BJ, Weis SE, et al. Transmission of drug-resistant tuberculosis in Texas and Mexico. J Clin Microbiol 2002; 40: 2716-2724.

8 European Centre for Disease Prevention and Control, WHO Regional Office for Europe. Tuberculosis surveillance and monitoring in Europe 2014. Stockholm, ECDC, 2014.

9 Falzon D, Infuso A, Aït-Belghiti F. In the European Union, TB patients from former Soviet countries have a high risk of multidrug resistance. Int J Tuberc Lung Dis 2006; 10: 954-958.

10 World Health Assembly. Resolution WHA67.1. Global strategy and targets for tuberculosis prevention, care and control after 2015. http://apps.who.int/gb/ebwha/pdf_files/WHA67/A67_R1-en.pdf

11 Van der Werf MJ, Langendam MW, Huitric E, et al. Multidrug resistance after inappropriate tuberculosis treatment: a meta-analysis. Eur Respir J 2012; 39: 1511-1519.

12 Lanzieri G. Fewer, older and multicultural? Projections of the EU populations by foreign/national background http://epp.eurostat.ec.europa.eu/cache/ITY_OFFPUB/KS-RA-11-019/EN/KS-RA-11-019-EN.PDF

13 US Census Bureau. International Migration is Projected to Become Primary Driver of U.S. Population Growth for First Time in Nearly Two Centuries. www.census.gov/newsroom/releases/archives/population/cb13-89.html Date last accessed: July 7, 2014. Date last updated: May 15, 2013.

14 Coleman D. The impact of immigration on the populations of the developed world and their ethnic composition. http://gt2030.com/2012/08/03/the-impact-of-immigration-on-the-populations-of-the-developed-world-and-theirethnic-composition/ Date last accessed: July 7, 2014.

15 Dye C, Williams BG, Espinal MA, et al. Erasing the world's slow stain: strategies to beat multidrug-resistant tuberculosis. Science 2002; 295: 2042-2046.

16 Ahuja SD, Ashkin D, Avendano M, et al. Multidrug resistant pulmonary tuberculosis treatment regimens and patient outcomes: an individual patient data meta-analysis of 9,153 patients. PLoS Med 2012; 9: e1001300.

17 Diel R, Vandeputte J, de Vries G, et al. Costs of tuberculosis disease in the European Union: a systematic analysis and cost calculation. Eur Respir J 2014; 43: 554-565.

18 Loddenkemper R, Sotgiu G, Mitnick CD. Cost of tuberculosis in the era of multidrug resistance: will it become unaffordable? Eur Respir J 2012; 40: 9-11.

19 World Health Organization. Tuberculosis (TB). www.who.int/tb/country/en

20 Centers for Disease Control and Prevention. Tuberculosis morbidity - United States, 1992. MMWR Morb Mortal Wkly Rep 1993; 42: 696-697.

21 Frieden TR, Fujiwara PI, Washko RM, et al. Tuberculosis in New York City - turning the Tide. N Engl J Med 1995; 333: 229-233.

22 Falzon D, Zignol M, Migliori GB, et al. Migration: an opportunity for the improved management of tuberculosis worldwide. Ital J Public Health 2012; 9: e7524.

23 Dara M, de Colombani P, Petrova-Benedict R, et al. The minimum package for cross-border TB control and care in the WHO European region: a Wolfheze consensus statement. Eur Respir J 2012; 40: 1081-1090.

24 Royce S, Falzon D, van Weezenbeek C, et al. Multidrug resistance in new tuberculosis patients: burden and implications. Int J Tuberc Lung Dis 2013; 17: 511-513.

25 Otero L, Krapp F, Tomatis C, et al. High prevalence of primary multidrug resistant tuberculosis in persons with no known risk factors. PLoS One 2011; 6: e26276.

26 Schwartzman K, Oxlade O, Barr RG, et al. Domestic returns from investment in the control of tuberculosis in other countries. N Engl J Med 2005; 353: 1008-1020.

27 Migliori GB, Sotgiu G, Gandhi NR, et al. Drug resistance beyond extensively drug-resistant tuberculosis: individual patient data meta-analysis. Eur Respir J 2013; 42: 169-179.

28 World Health Organization. Global tuberculosis report 2014 (WHO/HTM/TB/2014.08). Geneva, WHO, 2014.

29 Falzon D, Gandhi N, Migliori GB, et al. Resistance to fluoroquinolones and second-line injectable drugs: impact on MDR-TB outcomes. Eur Respir J 2013; 42: 156-168.

30 Migliori GB, De Iaco G, Besozzi G, et al. First tuberculosis cases in Italy resistant to all tested drugs. Euro Surveill 2007; 12: E070517.1.

31 Murase Y, Maeda S, Yamada H, et al. Clonal expansion of multidrug-resistant and extensively drug-resistant tuberculosis, Japan. Emerg Infect Dis 2010; 16: 948-954.

32 World Health Organization. Companion handbook to the WHO guidelines for the programmatic management of drug-resistant tuberculosis. (WHO/HTM/TB/2014.11). Geneva, WHO, 2014.

33 Toczek A, Cox H, du Cros P, et al. Strategies for reducing treatment default in drug-resistant tuberculosis: systematic review and meta-analysis. Int J Tuberc Lung Dis 2013; 17: 299-307.

34 Uffredi ML, Truffot-Pernot C, Dautzenberg B, et al. An intervention programme for the management of multidrug-resistant tuberculosis in France. Int J Antimicrob Agents 2007; 29: 434-439.

35 Blasi F, Dara M, Werf MJ, et al. Supporting TB clinicians managing difficult cases: the ERS/WHO Consilium. Eur Respir J 2013; 41: 491-494.

36 World Health Organization. A practical handbook on the pharmacovigilance of medicines used in the treatment of tuberculosis: enhancing the safety of the TB patient. www.who.int/medicines/publications/Pharmaco_TB_web_v3.pdf

37 World Health Organization. The use of bedaquiline in the treatment of multidrug-resistant tuberculosis. Interim policy guidance (WHO/HTM/TB/2013.6). http://apps.who.int/iris/bitstream/10665/84879/1/9789241505482_eng.pdf

38 Weyer K, Mirzayev F, Migliori GB, et al. Rapid molecular TB diagnosis: evidence, policy-making and global implementation of Xpert MTB/RIF. Eur Respir J 2013; 42: 252-271. 